\title{
The Revelation Research of Huawei Performance Management Mode to China's Private Enterprises
}

\author{
Mengmeng Shi, Zhenjian Jiang \\ College of Business, Shandong Architecture University, Jinan, China \\ Email: klesmm@163.com
}

How to cite this paper: Shi, M.M. and Jiang, Z.J. (2016) The Revelation Research of Huawei Performance Management Mode to China's Private Enterprises. Open Access Library Journal, 3: e3137.

http://dx.doi.org/10.4236/oalib.1103137

Received: October 12, 2016

Accepted: November 14, 2016

Published: November 17, 2016

Copyright $\odot 2016$ by authors and Open Access Library Inc.

This work is licensed under the Creative Commons Attribution International License (CC BY 4.0).

http://creativecommons.org/licenses/by/4.0/

(c) (i) Open Access

\begin{abstract}
Performance management plays a significant role in current business management. But with the changing environment and economic globalization, the competition among enterprises has become more furious than several years ago, and advanced performance management methods must be used in business management especially in human resource management field. In this paper, we try to analysis the problems existing in the performance management of China's private enterprises currently, and then research benchmark performance management mode of Huawei and thus illuminate suggestions in view of the performance management problem of private enterprises in Chinese. We hope this article would bring in new enlightenment ways for those in trouble enterprises.
\end{abstract}

\section{Subject Areas}

Business Analysis, General Business Research, General Management, Human Resource Management

\section{Keywords}

Huawei, Performance Management, China’s Private Enterprises

\section{Introduction}

Performance is the base to evaluate enterprise's development level, take source allocation and staff rewards and punishments. Moreover, the concept of performance management has been widely researched and applied since being proposed. And it reforms with the environment changing of the enterprises faces, which involves changing the traditional assessment system, assessment methods, and improving employee performance, etc. [1]. 
Under the economic globalization and Internet technology widely used era background, how to gain advantage in the fierce market competition is the most emphasized aspect of every enterprise. However, the competition among enterprise is the competition of human resources and each link of human resource management is closely related to performance management, which leads to performance management becoming the key to achieve success of corporations. Since China's reform and opening up, Chinese private enterprises with amazing courage and talent, have won rapid development and been a great part of Chinese contemporary enterprises. But with the enlargement of economic scale of private enterprises, human resources management issues have highlighted, such as the serious core brain drain problem and the low efficiency of performance evaluation process. What's worse, there lacks of a set of performance management system suitable for China's national conditions currently. Certainly, under the complex context, there have appeared excellent companies, such as the company of Huawei, Lenovo etc. And many enterprises are learning from those companies, including management method, management mode etc. In this paper, we try to analysis China's private enterprise performance problems under the new situation and study Huawei's performance management mode. We hope that this article would bring in enlightenment ways for some in trouble enterprises.

\section{The Problems of Private Enterprise Performance Management}

Performance management not only is a kind of method, but also a kind of thought. As a kind of method of performance management, it can provide managers with the convenience to management and examination employees, and improve the fairness. As a kind of thought of performance management it can help managers take more scientific decision-making and improve efficient and professional for manager's work, at the same time, help staffs to plan their own work and career better [2]. China's private enterprises pay more and more attention to performance management, and constantly according the performance management to work plan, but in practice, it brought more conflicts to managers and other management problems appeared constantly.

\subsection{Performance Management System Split from Enterprise Development Strategy}

Performance management is the important tool to realize enterprise strategy, is an important supporting part of corporate strategy, therefore, the enterprise performance management should conform to the enterprise's development strategy. However, many private enterprises performance management separate from development strategy, and even some private enterprises only pay attention to performance evaluation results, regard performance management as performance appraisal, eventually, making performance evaluation become a mere formality. What's worse, the most private enterprises just absorbed in performance management methods or focused on currently performance rating, instead of pay attention to analysis relation between performance management with corporate strategy. For example, in the private enterprises gathered place, the Pearl River Delta of China, according to survey about $85.9 \%$ of enterprises adopt 
performance management tool, but more than half of the enterprise is not fully understand it. And according to the respondents the performance plan, performance interviews and other activities of performance management process in approximately half enterprises become a mere formality [3]. As a result, the staff and department didn't agree with the enterprise's strategic goals and objectives, often appear department and individual performance is good except for enterprise performance.

\subsection{The Lack of Scientific Performance Management System}

Performance management system is a complete system, which include performance plan, performance coaching, performance assessment, performance feedback and the application of the evaluate results [4].

In each cycle, the lack of any link or incomplete would result in low level of performance management. Currently a lot of private enterprise performance management system is incomplete and mainly embodied in two aspects. One is that the internal of performance management system low participate of performance plan with employees and lack of performance communication, performance feedback, and the improve process according to the results of performance appraisal. According to the survey of pearl river delta of China's private enterprises present that about $48.4 \%$ the responds said performance plan were made without employee attend and more than $60 \%$ respondents said the enterprises don't have or occasional performance interviews. As for performance feedback, the manager of enterprises can discuss problems with employees and gives suggestions for improvement were $59.0 \%$, about $41.0 \%$ of visitors did not have this link. At the same time, the situation is similarly to the rest private enterprises of China. The two is it did not reflect relationship between performance management system and the rest of the organization's management system, which mainly includes the performance management appraisal content is not linked with the organization's goals, the result of performance appraisal feedback not to the use of other management system, as the important basis of organization to make decisions such as guidance of recruitment, training, position adjustment, modification job specifications, etc.

\subsection{Performance Communication Mechanism Is Not Perfect}

Private enterprises have different size and with complicated interpersonal relationship, which bring in more challenges for the assessed and more difficulty to guarantee fairness. The employees get different pay with same job and the phenomenon is relatively common. In addition, the original salary system design is not reasonable and performance appraisal is unfair, which easy to cause the oscillation of the enterprise. In order to ensure the performance management to be fair and reasonable, it is necessary to have a communication mechanism [5].

The effective communication mechanism can give employees a reasonable channel of express feelings and help to do the performance management work. Most of China's private enterprises have not been set up such communicate mechanism to monitor and 
receives the appeal, which can be evident from survey of the Pearl River delta of China that more than $60 \%$ respondents said the enterprises don't have or occasional performance interviews. Although there are some private enterprises set up such institutions, but often set unreasonable and play very limited role, the lack of effective supervision and complaint mechanism of the performance management make its fairness, impartiality is difficult to guarantee.

\subsection{The Low Efficiency of Performance Appraisal Process}

Performance appraisal is an important part of the performance management, however, many Chinese private enterprises in the implementation of performance appraisal fulfill with difficulty, such as mix the conception of performance management with performance appraisal which result in dissatisfied among managers and common employees and discourage efficient in workplace. At the same time, in the performance appraisal process, some private enterprises spend lots of time and energy take too frequently assessment, and the appraisal method in some private enterprises often is the superior to examine the lower or employee's self-assessment with limited appraisal information, which become the first perplex of Chinese professional managers according to a survey of the ten perplex to Chinese professional managers. At the same time, the inexperience and lower quality assessed and unscientific appraisal indicators increased the low efficiency of the performance evaluation process [6].

\section{The Performance Management Mode of Huawei}

\subsection{The Huawei's Performance Management Developing Course}

Huawei Technologies Corporation (Huawei) is a private enterprise which specializes in research and development (R\&D), production and marketing of communications equipment, and providing customized which was established by Ren zhenfei in 1988, shenzhen, China [7]. And now it is not only the industry's leader but also as the learning model to the rest of the world business. The achievements of Huawei cannot leave the performance management process, and the development of the performance management process is mainly divided into three stages: stage of personnel appraisal is popularization stage, the performance evaluation stage is the optimization stage, the last stage of sublimation for performance management, and these stages with Huawei's lifecycle is complementary to each other, the concrete content and evaluation purpose as shown in Table 1.

\subsection{The Performance Management Process of Huawei}

As a result of organizational and individual performance and value, performance management reveal the whole meaning of the organization and individual activities, the importance of performance is self-evident. The CEO of Huawei, Ren Zhengfei has repeatedly stressed to create a high performance corporate culture and performance culture is regarded as the enterprise survival and the source of development, which all depend on its advance performance management system. As is shown in Figure 1, the 


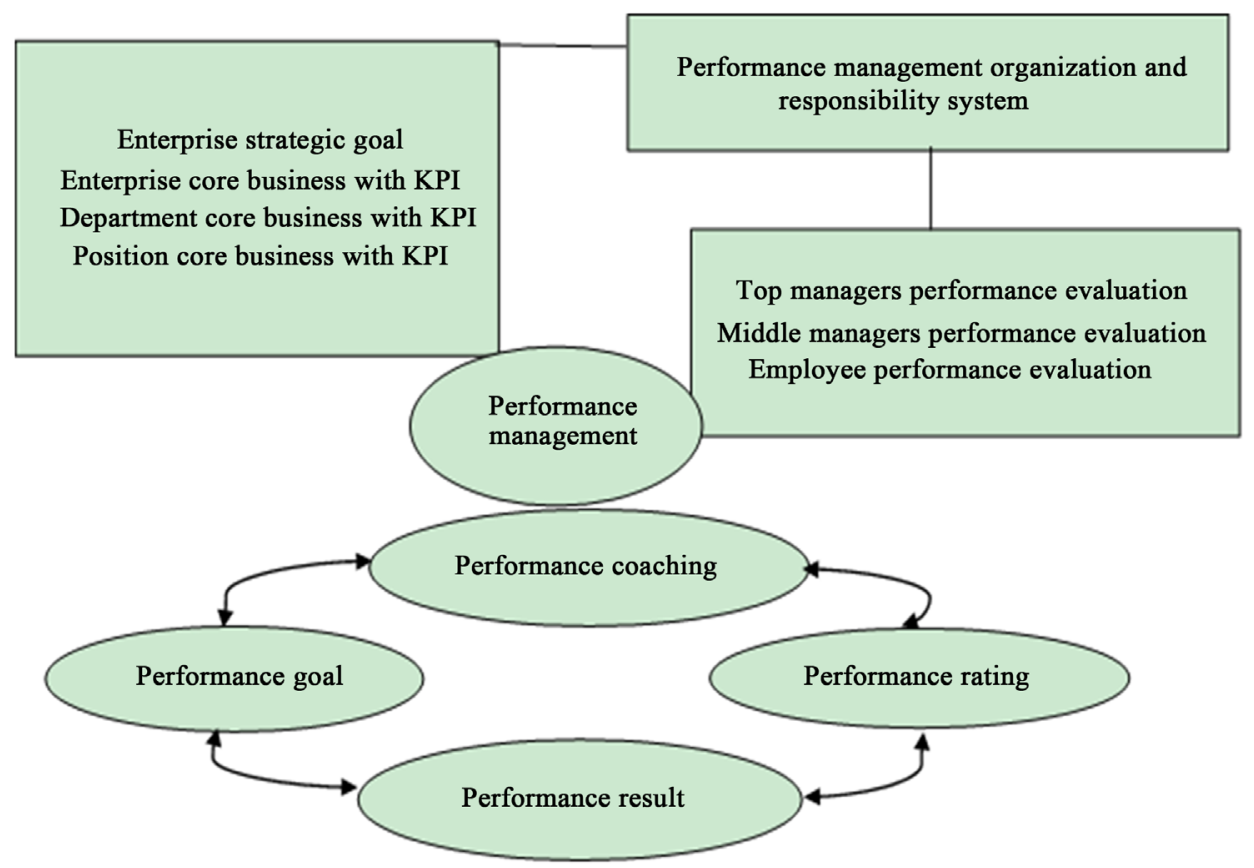

Figure 1. Performance management system of Huawei.

Table 1. Performance management stages of Huawei.

\begin{tabular}{|c|c|c|}
\hline Stages & The main evaluation content & Appraisal purpose \\
\hline $\begin{array}{l}\text { Personnel } \\
\text { appraisal } \\
\text { stage }\end{array}$ & $\begin{array}{l}\text { Including attitude, ability } \\
\text { and performance begin with } \\
\text { the Marketing Department }\end{array}$ & $\begin{array}{l}\text { Strengthen management } \\
\text { consciousness, to promote the } \\
\text { popularity of management concepts, } \\
\text { and improve the management level }\end{array}$ \\
\hline $\begin{array}{l}\text { Performance } \\
\text { appraisal } \\
\text { stage }\end{array}$ & $\begin{array}{l}\text { At this stage assess will as the tool } \\
\text { of performance evaluation, the content } \\
\text { of the assessment on performance }\end{array}$ & $\begin{array}{l}\text { Improved results orientation, } \\
\text { promote staff pragmatic, steadfast, } \\
\text { constantly raise the level of work }\end{array}$ \\
\hline $\begin{array}{l}\text { Performance } \\
\text { management } \\
\text { stage }\end{array}$ & $\begin{array}{l}\text { Performance appraisal is regarded as a system } \\
\text { of management process, add to new content } \\
\text { of the cross functional team assessment }\end{array}$ & $\begin{array}{c}\text { Improve self management consciousness, } \\
\text { the formation mechanism of } \\
\text { self-motivation and self-discipline }\end{array}$ \\
\hline
\end{tabular}

performance management system can guarantee fairness and efficient about performance management and stimulate employee's performance, which were implement in a circle with four segments (performance goal, performance coaching, performance rating, performance result). The performance management circle is begin with setting performance goal based on enterprise strategic goal and the goal including enterprise core business, department core business and position core business equip key performance indicators (KPI). In the process of performance appraisal, there have special performance management organization and responsibility system to supervision, implement and guarantee the effectiveness when take performance assessment among different levels of employees-including top managers, middle managers and general staffs-and also to be responsible for the improvement of performance management system. 


\subsubsection{Performance Goal}

At the beginning of each year, all employees in Huawei according to company strategic objectives signed the PBC (Personal Business Commitment), made detail work plan for all employees, and the company mainly according to the half-year cycle to design staff's $\mathrm{PBC}$ and secondary head's design for one year period. At the same time, executives and employees reach an agreement on performance appraisal target which is the combination of performance objectives, measure and improvement. In the process of set up performance goal we must obey SMART (Specific, Measurable, Attainable, Realistic, Time-based) principle and analysis internal and external environment of company facing [8].

\subsubsection{Performance Coaching}

It is mandatory in Huawei that managers at all levels should not be less than three times every six months to direct and guide employees with a formal interview and a detailed written record. Performance coaching mainly includes three aspects: performance diagnosis is to help employees improve work methods and skills. Process monitoring refers to the director within the department to establish and implement the system of "two-way communication", at any time to correct employee behavior and the feasibility of the target deviation. Data collection is to collect and record the employee behavior or the result of key events or data. So, on the one hand it can help to understand the status of the employee's work with the effect of the nip in the bud, on the other hand it will reduce the distance with employees and is conducive to stability and subsequent management.

\subsubsection{Performance Appraisal}

The performance evaluation mechanism of Huawei mainly includes three aspects: First is the liability result oriented and individual key events behavior result evaluation. Second is Hierarchical classification reporting on activities based on company strategy, namely the complete degree of commitment $\mathrm{PBC}$ and desired result. Third is based on the position qualification standards at all levels to investigate employee actual ability whether meet the requirements of office.

The emphasis of the assessment is different for different levels employees of Huawei. High-level managers should pay attention to enterprise long-term interests, the mainly appraisal way is reporting and KPI which is the combination of quarterly and annual reporting on activities. The grass-roots staff mainly focus on the completion of reality tasks and self-improvement, with assessment of IPBC, which is the combined of quarterly assessment and annual evaluation. And for ordinary employees, especially to measurement staff, review monthly. Under the fairness and equality principle it fully implements evaluation team system in the appraisal process. And it focuses on evaluation of the responsibility sense, mission sense, team spirit, skills, ideological and moral quality of workers.

\subsubsection{Performance Result}

Performance results as the main reference basis for an employee promotion, deploy- 
ment, assessment. At the same time it is the basis to eliminate the last one in Huawei. Evaluation results on the one hand take into the promotion and salary basis, on the other hand as part of the performance improvement, according to survey if there is gap between the expected goals and reality performance after evaluate and without staff performance communication in the late, the head of the department will be given red card to warning.

The basic purpose of performance appraisal is not to layoffs but to put employees in a suitable post through the examination, to ensure that everyone is able to achieve the ability of performance goals, and then through the realization of individual performance goals to complete the company's overall strategic objectives. There may be a variety of reasons lead to bad performance result, usually through training or relieve to another post to improve the performance. If it doesn't work eliminate will be work. We should memory in mind that performance result also is the beginning of next circle, and supervisor should pay attention to communication with the staff about performance result and next step planning goals [9].

\section{The Improvement Suggestions based on Huawei's Performance Management System}

Huawei become the leader of other companies, not only because the performance management process round in efficient cycle with internal performance plans, performance implementation and management, performance evaluation and performance feedback, but also because other aspects of human resource management combined in a whole. Performance management closely linked together with the enterprise's position system, qualification system, personnel selection and training system, salary management system. Therefore, other private enterprises of Chinese can figure out suggestions from the following aspects.

\subsection{Clear Performance Management Goal}

From the above analysis we can see that the performance management of enterprise is a system engineer process, which include a series cycle activities according to the target. And performance management is service for the development of enterprise, as a result, the performance management goal must be coordinated to enterprise's development and make full analysis, make accurate judgment to the development aim of enterprises, when carries out the performance system. So that we can eliminating barriers-not clear employees' purpose and uncertainty psychology elements-for late implementation of performance management. The managers of enterprises can follow these tips to gain explicit about their performance management goal. Firstly, make the performance management knowledge popularization for all employees. Secondly, introduce and cultivate performance management talents help to understand performance management goal, at the same time, promote the organization strategic target and encourage employees setting their own goals according to enterprise goal. Third, detail performance management process and improve the application of evaluation results to help the employee clear performance management goal. 


\subsection{Set up Perfect Performance Management System}

Performance management is a dynamic cycle system, which contains performance objectives, performance coaching, performance evaluation and application of performance results all of them closely linked together and any link disconnect will lead to the failure of performance management. Currently, there is a biggest problem in Chinese private enterprise that is the lack of scientific performance management system. And performance management is not equal to performance appraisal; performance appraisal is only a link in the performance management system. It is meaningful to set up perfect performance management system for realizing the strategic goal of private enterprises and great significance to improve the employee's work performance [10]. There are some tips to help improve performance management system for the private enterprises: a) the enterprises should take the enterprise strategy as guidance and ensure organization performance combined with employee performance, when formulating performance plans, b) the enterprises can combine qualitative indexes and quantitative indexes, not perfection just accords with the practice of enterprise development when take performance appraisal index, c) it is necessary to take flexible management of high frequency and rigid examination combined with low frequency in the performance evaluation, d) the enterprises should timely feedback to the reviewed evaluation results through the form of interviews after the performance assessment.

\subsection{To Establish a Scientific and Reasonable Performance Appraisal System}

Performance appraisal is the core of performance management, which can directly reflect the work and performance completion for employees. To establish scientific performance appraisal system, private enterprises can improve the following aspects.

First, choose the appropriate performance appraisal main body, it mainly includes the self-assessment, assessment of the superior, peer assessment, external evaluation and at a lower level evaluation several types, and different appraisal main body with different advantages and disadvantages, private enterprises must combine their own actual as well as the purpose of performance appraisal, to choose the appropriate performance appraisal main body. Second, set a reasonable performance appraisal interval, too frequently may waste enterprise's resources, too little may not reach the performance appraisal purpose. Therefore, the performance appraisal interval should be based on different employees' position and job nature in private enterprises, strive to science. Again, set up scientific and reasonable performance evaluation indicators, when set up performance appraisal index, private enterprises should highlight and make conveniently operation, and make the index of performance appraisal content real integrity, scientific and reasonable, at same time, and should adopt quantitative data as far as possible, avoid or reduce the index of those prone to understanding deviation. Last, training performance rater, as is shown in Huawei's performance appraisal system, it is a comprehensive scope including itself, superior and the same level altogether to appraisal and everyone understand clearly of significance and value to ap- 
praisal. So, in private enterprises it is necessary to train raters before performance assessment, the raters can truly realize the meaning and value of performance appraisal and clearly understand the performance appraisal content through training, eventually, using appropriate performance appraisal method [11].

\subsection{Establish an Effective Performance Management Communication Mechanism}

In the process of performance management, the lack of communication mechanism, can lead to assessed rights abuse, thus caused controversy and disputes. Particularly, private enterprises should pay attention to build performance management communication mechanism. Because of the enterprise managers tend to be the founder of the company, or its members of the family may abuse their manage rights. Therefore, it is necessary to private enterprises to set up effective communication channels, in order to avoid managers from the frontline staff. In specifically, on the one hand, the enterprises encourage employees take part in formulate performance planning and performance appraisal process, on the other hand, managers should be constantly communicate with employees, find the problems in the process of assessment and should be timely feedback to employees, at the same time, provide useful information, discuss countermeasures, help employees improve performance and complete performance targets [12].

\section{Conclusion and Recommendations for Further Research}

As a leader private enterprise in China, Huawei's advance performance management model provides us with a lot of revelation, for example all attend to formulate with performance planning and every employee makes their own goal combined with enterprise's strategy goal. Moreover, with scientific performance appraisal indicator system it not only guarantees fairness and effectiveness appraisal results but also provides basis for managers in promote, reward and punish, and at the same time, efficient and timely performance feedback and interview can help the employee clearly understand performance assessment goal and know how to improve their performance for the rest work. Also other aspects, such as its unique management methods with military culture system, in some extent, help to implement its performance management system. But, it may be an effective performance management model in a certain period. In the long run, other enterprises should seek for performance management system that is effective to their special enterprise culture and management system. Therefore, other enterprises not only need to learn from other advanced management system land methods, just like Huawei, but also need to build the cultural of innovation.

Although the thesis analyzes some urgent problems that exist in current private enterprises of Chinese and based on Huawei's performance management system, provides some improvement suggestions. There are several aspects that need to be studied deeply in the future about this subject, for example the description is not comprehensive and specific about the mode of Huawei's performance management system and lacks of data and empirical research evidence. At the same time, the analysis in recommended 
suggestions can be detailed in specific tips with some tools, just like how to evaluate efficiently with scientific indicators, which all need further research.

\section{References}

[1] Cappelli, P. and Tavis, A. (2016) The Performance Management Revolution. Harvard Business Review, 10, 58-67.

[2] Goncharuk, A. (2011) Making the Mechanism of Enterprise Performance Management. Journal of Economia Seria Management, 14, 58-72.

[3] Zhang, M.H. (2015) The Performance Management Present Situation and the Countermeasure Study of Small and Medium-Sized Private Enterprises in the Pearl River Delt. Human Resource Development, 5, 75-76.

[4] Lebas, M.J. (1995) Performance Measurement and Performance Management. International Journal of Production Economics, 41, 23-35. http://dx.doi.org/10.1016/0925-5273(95)00081-X

[5] Foba, T.W. and Villiers, D.D. (2007) The Integration of Intrapreneurship into a Performance Management Model. South African Journal of Human Resource Management, 5, 18. http://dx.doi.org/10.4102/sajhrm.v5i2.114

[6] Buckingham, M. and Goodall, A. (2015) Reinventing Performance Management. Harvard Business Review, 4, 40-50.

[7] Milano, P.D. (2011) Internationalization of Chinese MNEs and Italy Market Analysis: A Case Study of Huawei Technologies Corporation's Internationalization Strategy. Master Thesis, Politecnico Di Milano, Italy.

[8] Neely, A., Gregory, M. and Platts, K. (1995) Performance Measurement System Design: A Literature Review and Research Agenda. International Journal of Operations \& Production Management, 15, 80-116. http://dx.doi.org/10.1108/01443579510083622

[9] Zhu, B. (2008) Internationalization of Chinese MNEs and Dunning's Eclectic (OLI) Paradigm: A Case Study of Huawei Technologies Corporation's Internationalization Strategy. Master Thesis, School of Economics and Management Department of Economics, Lund University, Sweden.

[10] Ensslin, S., Ensslin, L., Lacerda, R. and Souza, V. (2014) Disclosure of the State of the Art of Performance Evaluation Applied to Project Management. American Journal of Industrial and Business Management, 4, 677-687. http://dx.doi.org/10.4236/ajibm.2014.411073

[11] Namada, J., Aosa, E., Awino, Z. and Wainaina, G. (2014) Management Participation and Firm Performance. American Journal of Industrial and Business Management, 4, 113-122. http://dx.doi.org/10.4236/ajibm.2014.43018

[12] Spangenberg, H.H. (1994) Performance Management-Problems and Possible Solutions. Sa Journal of Industrial Psychology, 20, 1-6. http://dx.doi.org/10.4102/sajip.v20i1.566 
Submit or recommend next manuscript to OALib Journal and we will provide best service for you:

- Publication frequency: Monthly

- 9 subject areas of science, technology and medicine

- Fair and rigorous peer-review system

- Fast publication process

- Article promotion in various social networking sites (LinkedIn, Facebook, Twitter, etc.)

- Maximum dissemination of your research work

Submit Your Paper Online: Click Here to Submit

Or Contact service@oalib.com 